Article

\title{
Effect of Curing Agent and Temperature on the Rheological Behavior of Epoxy Resin Systems
}

\section{Chenhui Zhao *, Guangcheng Zhang and Lei Zhao}

School of Natural and Applied Science, Northwestern Polytechnical University, Xi' an 710072, China; E-Mails: zhangguc@nwpu.edu.cn (G.Z.); irayson@163.com (L.Z.)

* Author to whom correspondence should be addressed; E-Mail: zhaohui18201@163.com; Tel.: +86-029-8843-1680.

Received: 15 May 2012; in revised form: 7 July 2012 / Accepted: 10 July 2012 /

Published: 17 July 2012

\begin{abstract}
The effect of curing agent (6610) content and temperature on the rheological behavior of the epoxy resin CYD-128 was studied by DSC analysis and viscosity experiments. The results show that the resin system meets the requirements of processing technology. A complete reaction occurs when the curing agent content (40 parts per hundred resin, phr) is a little higher than the theoretical value (33.33 phr), while the degree of reaction of the resin system is reduced when the curing agent content is lower (25.00 phr) than theoretical value. However, excessive curing agent (50.00 phr) results in a lower reaction rate. Curing agent content has little influence on gel time when curing agent content exceeded $33.33 \mathrm{phr}$ and the temperature was less than $70{ }^{\circ} \mathrm{C}$. The isothermal viscosity-time curves shift towards the $-\mathrm{x}$ axis when the temperature rises from $50{ }^{\circ} \mathrm{C}$ to $80{ }^{\circ} \mathrm{C}$. Meanwhile, higher temperature results in higher reaction rates.
\end{abstract}

Keywords: epoxy resins; cure kinetics; curing agent; rheological behavior

\section{Introduction}

Epoxy resins are commonly used as polymeric matrices in high-performance composites [1]. Epoxy resins is used extensively due to their low shrinkage, high adhesive strength, adjustable functional structure and better mechanical performance, especially in fields that require high strength and excellent performance such as wind blades and aerospace engineering [2-5]. 
There are many steps involved in the production process, from the selection of raw materials to the manufacture of the finished products. Of the many steps involved, the processing step plays a pivotal role in determining the quality of the final products [6,7]. The mechanism and kinetics of cure determine the network morphology, which, in turn, dictates the physical and mechanical properties of the cured product. Thus, understanding the cure kinetics of thermosets is essential for process development and quality control [8]. Perhaps the most important properties of polymeric materials with respect to their processing behavior are the rheological behavior. Viscosity control during processing of thermosets is particularly critical because the viscosity varies not only with temperature and flow conditions, but also with time because of polymerization reactions. Therefore, a comprehensive understanding of the relationship between the curing kinetics and rheological behavior is necessary to effectively control the cure process and to optimize the processing schedules and the properties of the finished product.

Despite the extensive literature on the polymerisation/curing of epoxy resins with amines, detailed studies on the effects of curing agent ratio on the curing kinetic and viscosity of a special system are generally not available [9-21]. The present study was carried out in order to determine the relationship between curing agent ratio and rheological behavior of the resin system.

\section{Results and Discussion}

\subsection{Effect of Curing Agent Content on Curing Characteristics}

DSC curves of resin systems with 25, 33.3 and 40 phr of curing agent are shown in Figure 1, and the heats of reactions $(\Delta H)$, start temperature $(T s)$, end temperature $(T e)$ and peak temperature $(T p)$ are reported in Table 1.

Figure 1. DSC curves at different curing agent content.

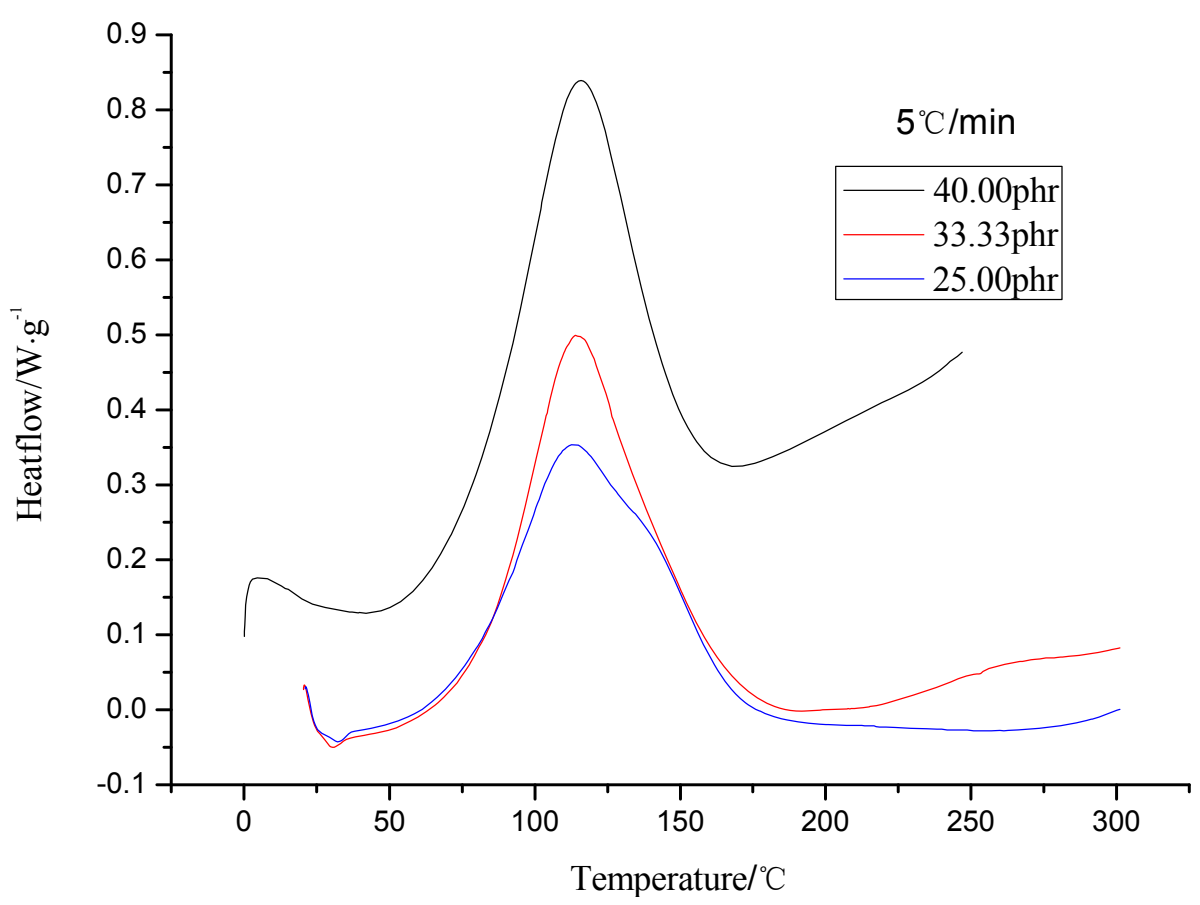


Table 1. DSC results of different curing agent phr.

\begin{tabular}{ccccc}
\hline Phr of curing agent & $\boldsymbol{T s}\left({ }^{\circ} \mathbf{C}\right)$ & $\boldsymbol{T p}\left({ }^{\circ} \mathbf{C}\right)$ & $\boldsymbol{T e}\left({ }^{\circ} \mathbf{C}\right)$ & $\Delta \boldsymbol{H}(\mathbf{J} / \mathbf{g})$ \\
\hline 40.00 & 37.97 & 113.54 & 174.12 & 335.7 \\
33.33 & 43.07 & 116.97 & 209.79 & 315.4 \\
25.00 & 47.23 & 122.57 & 215.10 & 275.6 \\
\hline
\end{tabular}

It can be found there is wide exothermic peak, as shown in Figure 1, and we can also obtain the information from Table 1 that $\Delta H$ ranges from 275.6 to $335.7 \mathrm{~J} / \mathrm{g}$ which implies a low heat release. The combination of these two results indicate that the resin system meet the processing technology requirements. $\Delta H$ from Table 1 indicates that a complete reaction occurs when the curing agent content (40 phr) is higher than theoretical value (33.33 phr), while the degree of reaction of the resin system reduces when the curing agent content is lower $(25 \mathrm{phr})$ than the theoretical value.

\subsection{Effect of Temperature and Curing Agent Content on Resin System Viscosity}

This paper studied the isothermal viscosity-time curves over a temperature range from 50 to $80{ }^{\circ} \mathrm{C}$ for different curing agent contents $(33.33,40.00$ and $50.00 \mathrm{phr})$. The results are shown in Figures 2-5. The curves displayed in Figures 2 and 3 show the same shape, which suggests the same cure kinetic mechanism for each system. It can also be observed that all the curves show the same functional form, only shifted by a constant factor along the $\mathrm{x}$ (time) axis. It follows that all the curves at different temperatures should be the same shape by simply shifting each curve along the $\mathrm{x}$ (time) axis relative to a curve at an arbitrary reference temperature by a shift factor [1]. Meanwhile, the slopes of the curves are different from each other. The slope increases as the temperature rises, which represents the reaction rate of the system. The difference of the slope indicates the temperature dependence of the reaction. Higher temperature results in higher reaction rate. This is similar to the report by Mounif et al. [22].

Figure 2. Viscosity of resin system with $50.00 \mathrm{phr}$ curing agent at different temperature.

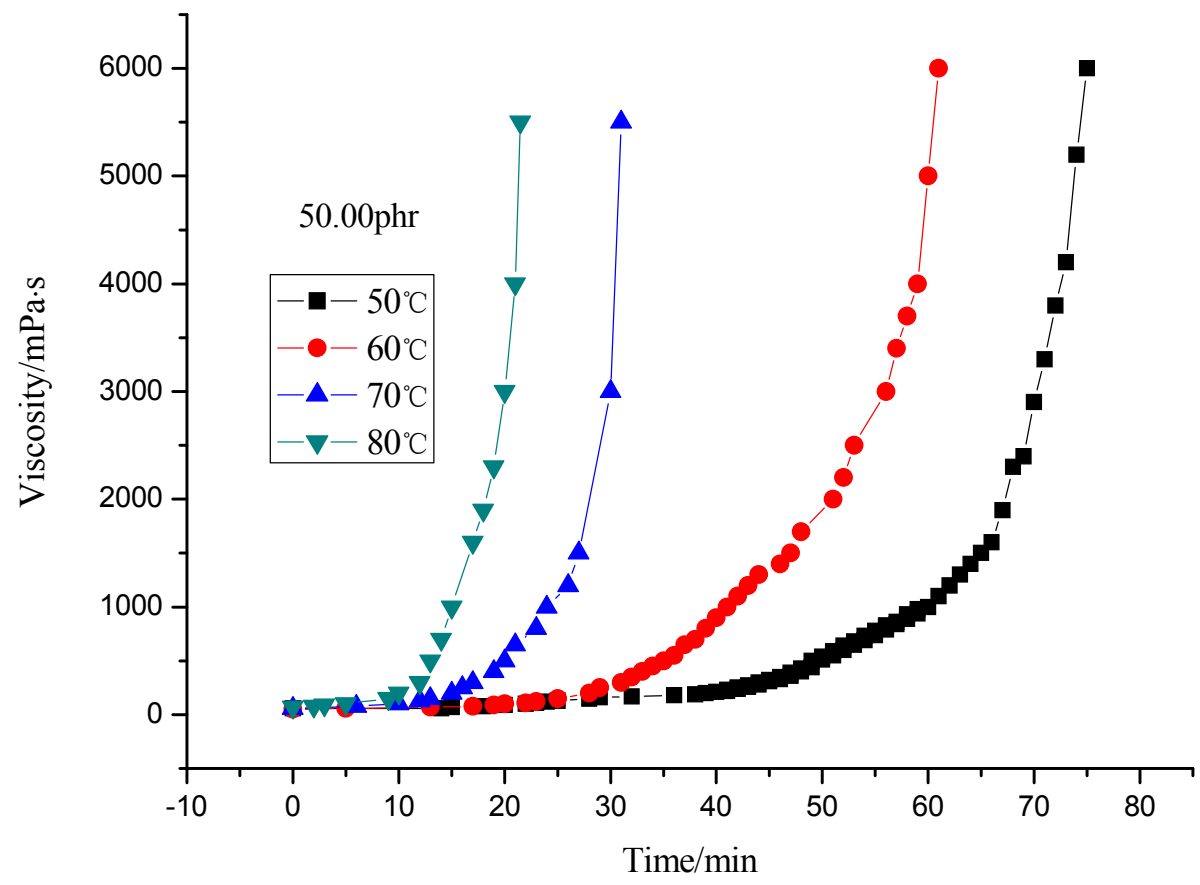


Figure 3. Viscosity of resin system with $33.33 \mathrm{phr}$ curing agent at different temperature.

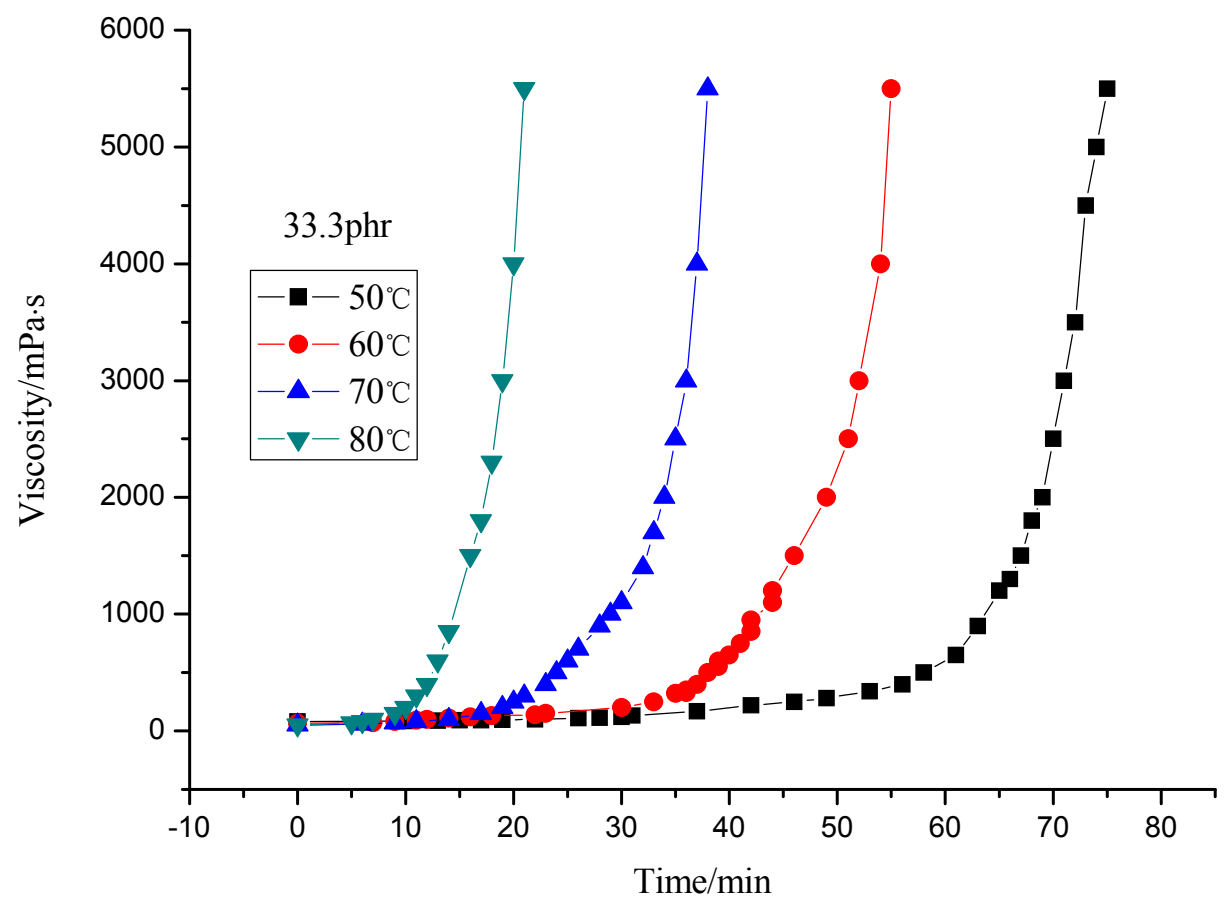

Both Figures 4 and 5 indicate that the viscosity of the system with $40 \mathrm{phr}$ curing agent rises faster than that with $33.33 \mathrm{phr}$ (theoretical value), which may be caused by excess curing agent, but the viscosity rise rate slows when more curing agent is added $(50 \mathrm{phr})$, the reason may be that excessive curing agent dilutes the resin which in turn hinders the crosslinking reaction.

Figure 4. Viscosity of resin system with different curing agent content at $70{ }^{\circ} \mathrm{C}$.

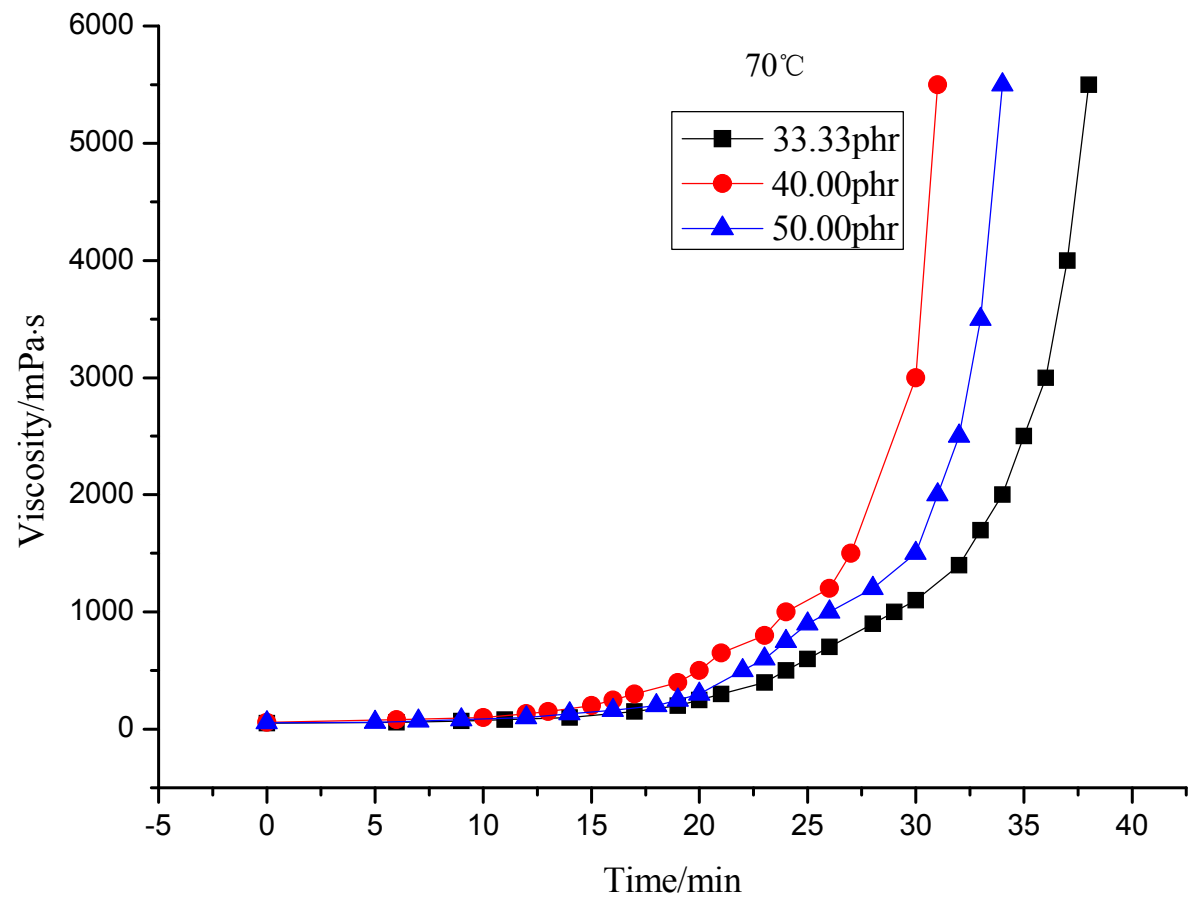


Figure 5. Viscosity of resin system with different curing agent content at $80{ }^{\circ} \mathrm{C}$.

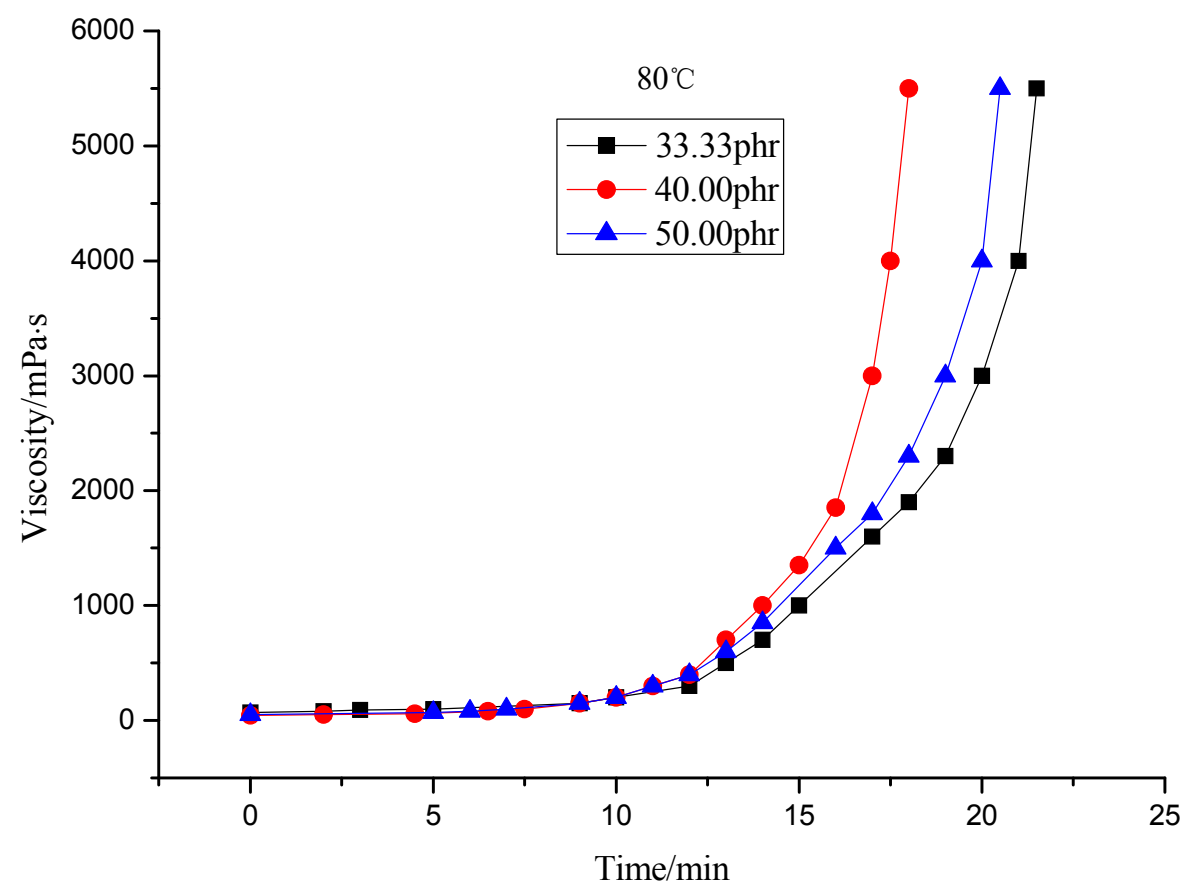

\subsection{Effect of Curing Agent Content on Gel Time}

Gel time is one of the most important parameters in any molding process. The gel time reflects the activity of system according to temperature. Measurements are performed in constant temperature. In this process, the influence of curing agent content $(28.57,33.33,40.00$ and $50.00 \mathrm{phr})$ on the gel time of the epoxy resin at different temperatures $\left(50,60,70\right.$ and $80^{\circ} \mathrm{C}$ ) was tested (Figure 6).

Figure 6. Relationship between gel time and curing agent content.

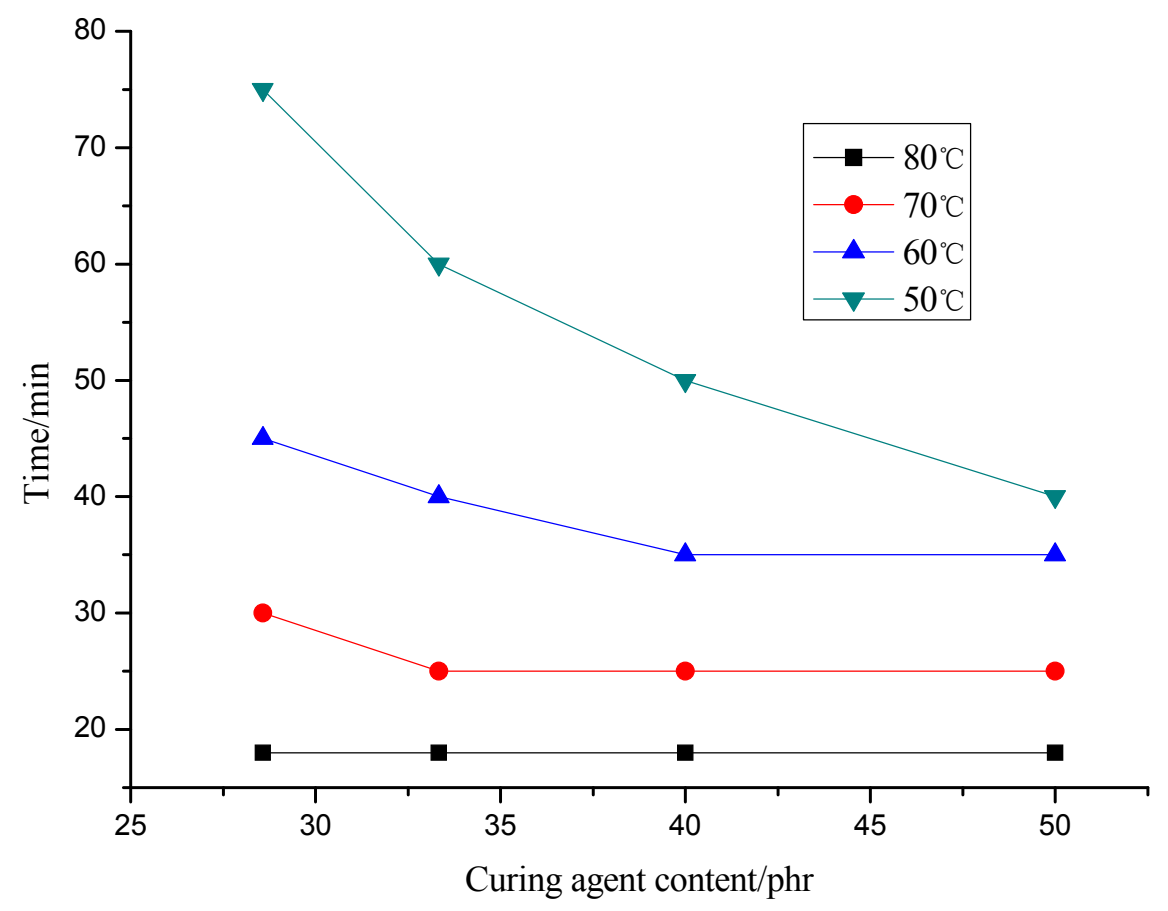


It shows that the curing agent content has little effect on gel time when the temperature is less than $70{ }^{\circ} \mathrm{C}$ and curing agent content exceeds $33.33 \mathrm{phr}$. On the contrary, when the temperatures are below $70{ }^{\circ} \mathrm{C}$ and curing agent content is less than $33.33 \mathrm{phr}$, gel time increases with the decreasing curing agent content at the same temperature; gel time shortens with the rising of constant temperature at the same phr of curing agent.

\section{Experimental}

\subsection{Experiment Preparation}

The rheological behavior of the system diglycidyl bisphenol-A (CYD-128, Viscosity: 11,000-14,000 mpas at $25{ }^{\circ} \mathrm{C}$, Exoxy value: $0.51-0.54 \mathrm{~mol} / 100 \mathrm{~g}$ ) and amine curing agent (6610, amine value: $280 \pm 20 \mathrm{mg} \mathrm{KOH} / \mathrm{g}$ ) was studied by both differential scanning calorimetry (DSC) and rheometry. The components were mixed at room temperature by an electric mixer (Type: 6511, Shanghai Specimen Model Factory, Shanghai, China) at room temperature and degassed under vacuum for $15 \mathrm{~min}$. The resulting resin mixtures were either tested immediately or stored at $-40{ }^{\circ} \mathrm{C}$ in a dry-box containing silica gel. When samples were removed from the refrigerator they were allowed to warm to room temperature before being placed in hermetically sealed aluminum pans.

\subsection{Experimental Procedures}

Kinetic studies of samples prepared using 25.00, 33.33 and $50.00 \mathrm{phr}$ of curing resin which were sealed in aluminum pans with weights in the range $5-15 \times 10^{-3} \mathrm{~g}$ were carried out using DSC (TA Instrument-2910, New Castle, DE, USA) at the heating rate of $5{ }^{\circ} \mathrm{C} / \mathrm{min}$, and all kinetic studies were performed under a nitrogen atmosphere The viscosities of the resin system containing either 33.33, 40.00 or $50.00 \mathrm{phr}$ of curing agent and subjected to isothermal curing at different temperatures $(50,60$, 70 and $80^{\circ} \mathrm{C}$ ) were measured by a rotational viscometer (NDJ-7, Shanghai Changji Geological Instruments Co., Ltd., Shanghai, China). The gel time is determined by wire drawing.

\section{Conclusions}

In this work, the effect of the curing agent content on cure kinetics and rheological behavior of a resin system was studied. The results indicate that the resin system meet the requirements of processing technology; a complete reaction occurs when the curing agent content is higher (40 phr) than theoretical value and excessive curing agent $(50.00 \mathrm{phr})$ results in lower reaction rates. The isothermal viscosity-time curves shift towards the $-\mathrm{x}$ axis when the temperature rises. Curing agent content has little influence on gel time when the temperature is lower than $70{ }^{\circ} \mathrm{C}$ and curing agent content exceeds $33.33 \mathrm{phr}$.

\section{Acknowledgments}

Financial support from NWPU Basic Research Fund (JC201274, 2012) is gratefully acknowledged. 


\section{References}

1. Dispenza, C.; Carter, J.; McGrail, P.; Spadaro, G. Cure behaviour of epoxy resin matrices for carbon fibre composites. Polym. Int. 1999, 48, 1229-1236.

2. Zhou, G.; Movva, S.; Lee, L.J. Nanoclay and long-fiberreinforced composites based on epoxy and phenolic resins. J. Appl. Polym. Sci. 2008, 108, 3720-3726.

3. Xu, Y.; Hoa, S.V. Mechanical properties of carbon fiber reinforced epoxy/clay nanocomposites. Compos. Sci. Technol. 2008, 68, 854-861.

4. Chatterjee, A.; Gillespie, J.W., Jr. Room temperature-curable VARTM epoxy resins: Promising alternative to vinyl ester resins. J. Appl. Polym. Sci. 2010, 115, 665-673.

5. Green, K.J.; Dean, D.R.; Vaidya, U.K.; Nyairo, E. Multiscale fiber reinforced composites based on a carbon nanofiber/epoxy nanophased polymer matrix: Synthesis, mechanical, and thermomechanical behavior. Compos. Part A 2009, 40, 1470-1475.

6. Wen, X.F.; Wang, X.F.; Cai, Z.Q.; Pi, P.H.; Cheng, J.; Yang, Z.R. Cure kinetics and chemorheological behavior of a wind epoxy resin system and its viscoelastic properties reinforced by glass fiber matt with process of vacuum assisted resin transfer molding. High Perform. Polym. 2011, 23, 477-484.

7. Halley, P.J.; Mackay, M.E. Chemorheology of thermosets-An overview. Polym. Eng. Sci. 1996, 36, 593-609.

8. Ivankovic, M.; Incarnato, L.; Kenny, J.M.; Nicolais, L. Curing kinetics and chemorheology of epoxy/anhydride system. J. Appl. Polym. Sci. 2003, 90, 3012-3019.

9. Shi, F.; Duan, Y.X.; Zeng, X.N.; Lang, Z.Y.; Zhang, Z.G. Rheological behaviors and viscosity model of Bisphnol-A Epoxy/DDS Resin system. Acta Aeronaut. Astronaut. Sin. 2005, 26, 610-616.

10. Martínez, P.C.; García, M.F.; de la Fuente, J.L. Rheological cure characterization of a polyfunctional epoxy acrylic resin. React. Funct. Polym. 2010, 70, 761-766.

11. O'Brien, D.J.; White, S.R. Cure kinetics, gelation, and glass transition of a bisphenol F epoxide. Polym. Eng. Sci. 2003, 43, 863-874.

12. Teyssandier, F.; Ivanković, M.; Love, B.J. Modeling the effect of the curing conversion on the dynamic viscosity of epoxy resins cured by an anhydride curing agent. J. Appl. Polym. Sci. 2010, $115,1671-1674$.

13. Yang, J.S.; Xiao, J.Y.; Jiang, D.Z.; Zeng, J.C.; Liu, J.; Peng, C.Y. Rheological model and behaviors of resin system for vacuum infusion molding process. Acta Mater. Compos. Sin. 2009, $26,1-7$.

14. Ning, B.J.; Ning, R.C. Research of a new kind epoxy resin room temperature curing system. Chin. J. Explos. Propellants 2006, 29, 62-64.

15. Guo, Z.S.; Du S.Y.; Zhang, B.M.; Wu Z.J.; Li, F.; Fu, Q.L. Cure Kinetics and Chemorheological Behavior of Epoxy Resin used in Advanced Composites. Acta Mater. Compos. Sin. 2004, 21, 146-151.

16. Shi, F.; Duan, Y.X.; Zeng, X.N.; Lang, Z.Y.; Zhang, Z.G. Engineering viscosity model for Bisphenol-A epoxy resin/catalytic curing agent system. Acta Mater. Compos. Sin. 2005, 22, $72-79$. 
17. Yang, J.S.; Xiao, J.Y.; Zeng, J.C.; Liu, X.Y.; Chen, H.S.; Chen, H. Rheological behavior of resin system for composite wind blades. J. WuHan Univ. Technol. 2009, 21, 125-128.

18. Yang, J.S.; Xiao, J.Y.; Zeng, J.C.; Peng, C.Y. Study on rheological behavior of unsaturated polyester resin system. J. Mater. Eng. 2009, 12, 62-66.

19. Zhang, M.; Xu, Y.H.; Xing, J.; An, X.F.; Yi, X.S. Study on rheological behavior of 3266 epoxy for resin transfer m olding. J. Mater. Eng. 2005, 6, 50-53.

20. Ding, Y.Y.; Jia, Y.X.; Yang, J.Y.; He, H.D.; Sun, S.; Shi, T.F. Correlation analysis of epoxy/amine resin cure, structure and chemorheological behavior in RTM processes. Polym. Compos. 2011, 32, 648-656.

21. Domínguez, J.C.; Alonso, M.V.; Oliet, M.; Rojo, E.; Rodríguez, F. Kinetic study of a phenolicnovolac resin curing process by rheological and DSC analysis. Thermochim. Acta 2010, 498, $39-44$.

22. Mounif, E.; Bellenger,V.; Mazabraud, P.; Nony, F.; Tcharkhtchi, A. Chemorheological study of DGEBA/IPD system for reactive rotational molding (RRM). J. Appl. Polym. Sci. 2010, 116, 969-976.

Sample Availability: Not available.

(C) 2012 by the authors; licensee MDPI, Basel, Switzerland. This article is an open access article distributed under the terms and conditions of the Creative Commons Attribution license (http://creativecommons.org/licenses/by/3.0/). 